\title{
Surgical resection for patients with pulmonary aspergillosis in the national inpatient sample
}

\author{
Deven C. Patel ${ }^{1} \wedge$, Prasha Bhandari ${ }^{1}$, David J. Epstein ${ }^{2}$, Douglas Z. Liou ${ }^{1}$, Leah M. Backhus ${ }^{1,3}$, \\ Mark F. Berry ${ }^{1,3}$, Joseph B. Shrager ${ }^{1,3}$, Natalie S. Lui ${ }^{1}$ \\ ${ }^{1}$ Department of Cardiothoracic Surgery, Stanford University Medical Center, Stanford, CA, USA; ${ }^{2}$ Department of Medicine/Infectious Diseases, \\ Stanford University Medical Center, Stanford, CA, USA; ${ }^{3}$ VA Palo Alto Health System, Palo Alto, CA, USA \\ Contributions: (I) Conception and design: DC Patel, P Bhandari, DJ Epstein, NS Lui; (II) Administrative support: DC Patel, P Bhandari, NS Lui; (III) \\ Provision of study materials or patients: DC Patel, P Bhandari, NS Lui; (IV) Collection and assembly of data: DC Patel, P Bhandari, DJ Epstein, NS \\ Lui; (V) Data analysis and interpretation: All authors; (VI) Manuscript writing: All authors; (VII) Final approval of manuscript: All authors. \\ Correspondence to: Natalie S. Lui, MD. 300 Pasteur Drive, Falk Cardiovascular Research Institute, Stanford, CA 94305, USA. \\ Email: natalielui@stanford.edu.
}

Background: The role of lung resection in patients with pulmonary aspergillosis is generally reserved for those with localized disease who fail medical management. We used a national database to investigate the influence of preoperative patient comorbidities on inpatient mortality and need for surgery.

Methods: Patients admitted with pulmonary aspergillosis between 2007 to 2015 were identified in the National Inpatient Sample dataset. Inpatient mortality rates were compared between patients treated medically and surgically. Predictors of mortality, surgical intervention, and non-elective admission were evaluated using multivariable logistic regression.

Results: Among a population estimate of 112,998 patients with pulmonary aspergillosis, 107,606 (95.2\%) underwent medical management alone and 5,392 (4.8\%) underwent surgical resection. Positive predictors for surgery included hemoptysis, and history of lung cancer or chronic pulmonary diseases. Surgically treated patients had a lower inpatient mortality when compared to those treated medically $(11.5 \%$ vs. $15.1 \%$, $\mathrm{P}<0.001$ ) in univariate analysis, but this finding did not persist in multivariable analysis (AOR 0.97, $\mathrm{P}=0.509$ ). The odds of mortality were lower in patients undergoing video assisted thoracoscopic surgery compared to an open approach (AOR 0.77, $\mathrm{P}=0.001$ ). Among patients treated surgically, mortality was higher in those with a history of lung cancer, solid organ transplantation, liver disease, human immunodeficiency virus infection, hematologic diseases, chronic pulmonary diseases, and those admitted non-electively requiring surgery.

Conclusions: In this generalizable study, medical and surgical management of pulmonary aspergillosis were comparable in terms of inpatient mortality. However, non-elective admission and patients with select comorbidities have significantly worse outcomes after surgical intervention.

Keywords: Pulmonary aspergillosis; surgery; mortality; risk factors; non-elective admission

Submitted Feb 17, 2021. Accepted for publication Jul 23, 2021.

doi: $10.21037 /$ jtd-21-151

View this article at: https://dx.doi.org/10.21037/jtd-21-151

\footnotetext{
^ ORCID: 0000-0002-8883-3546.
} 


\section{Introduction}

Infection due to Aspergillus accounts for nearly 40,000 annual hospital admissions in the United States $(1,2)$. Primarily acquired via inhalation of airborne spores, it is a ubiquitous mold commonly found in organic debris, dust, compost, foods, and plants. A spectrum of pulmonary disease syndromes exist, including aspergilloma (typically within an existing cavity), chronic pulmonary aspergillosis (CPA), and invasive pulmonary aspergillosis (IPA) $(3,4)$. Allergic bronchopulmonary aspergillosis (ABPA), a hypersensitivity syndrome in response to fungal antigens, is distinct to other forms of pulmonary aspergillosis in terms of pathophysiology and treatment. The interaction between this pathogen and host immune dysfunction largely determines the clinical manifestation likely to develop (5). Pulmonary aspergillosis, particularly IPA, is associated with significant morbidity and mortality, often a consequence of a necrotizing bronchopneumonia with invasion of pulmonary parenchyma and nearby blood vessels $(2,5)$. Angioinvasion is particularly morbid as it can lead to thrombosis, hemorrhage, and hematogenous dissemination (6).

With the advent of new antifungal drugs and tools allowing early diagnosis, pulmonary aspergillosis is often treated medically $(7,8)$. Surgical intervention is usually reserved for patients with persistent symptomatic localized disease (refractory to medical management) and those with hemoptysis $(9,10)$. Medically treated IPA is reportedly associated with mortality rates ranging from $30-90 \%$, while surgically treated patients tend to have lower mortality ranging from $10-31 \%(6,11-15)$. Some have advocated for early surgery, arguing that early local control through safe procedures can prevent progression of infection and its sequelae $(6,9,16-18)$. These promising results are limited to single institutional series, restricting the generalizability and inferences that can be made due to small sample sizes. Therefore, we sought to delineate the differences in outcomes of patients with pulmonary aspergillosis treated medically and surgically in a large national database, specifically examining inpatient mortality. Furthermore, as early surgical intervention may improve outcomes, we sought to identify specific patient risk factors that may be associated with the need for surgical intervention.

We present the following article in accordance with the STROBE reporting checklist (available at https://dx.doi. org/10.21037/jtd-21-151).

\section{Methods}

\section{Data source}

The study was conducted in accordance with the Declaration of Helsinki (as revised in 2013). Patients admitted with pulmonary aspergillosis were identified using the National Inpatient Sample (NIS) database. The NIS is the largest publicly available all-payer inpatient healthcare database in the United States (US), and, by estimating more than 40 million weighted hospitalizations annually, is considered to be an accurate representation of the national inpatient population (19). The NIS approximates a $20 \%$ stratified sample of discharges from US community hospitals, excluding rehabilitation and long-term acute care hospitals (20). Comprehensive information on all hospital admissions, regardless of expected payer, are collected within the dataset. Since all data within the NIS database is deidentified, this study was considered exempt by our Institutional Review Board.

\section{Patient selection}

All procedure codes for this study are based on the International Classification of Diseases, $9^{\text {th }}$ edition (ICD-9). In order to maintain consistency in our data coding, we utilized the NIS datasets for 2007 through the third quarter of 2015, at which point the International Classification of Diseases coding was switched from ICD9 to ICD-10. Patients with pulmonary aspergillosis were identified using ICD-9 codes 117.3 (aspergillosis) and 484.6 (pneumonia in aspergillosis). Patients with sinusitis (461.X and 473.X) and ABPA (518.6) codes were excluded. Additionally, minors and patients with missing vital status or procedural data were excluded.

Patients were classified into the surgical management cohort if the principal or any secondary procedures codes associated with admission described an open $(32.9,32.4,32.49$, $32.29,32.39,32.9,32.5,32.59)$ or video-assisted thoracoscopic (VATS) $(32.20,32.25,32.28,32.41,32.50)$ lung resection. Of note, patients treated surgically were presumably also being treated with antifungal medications as this is the widely accepted standard of care $(5,7)$. Patients without any of the aforementioned pulmonary surgical procedure codes were considered as undergoing medical management alone. The two cohorts were compared in terms of demographics, Charlson comorbidity score, hospital admission characteristics, and 


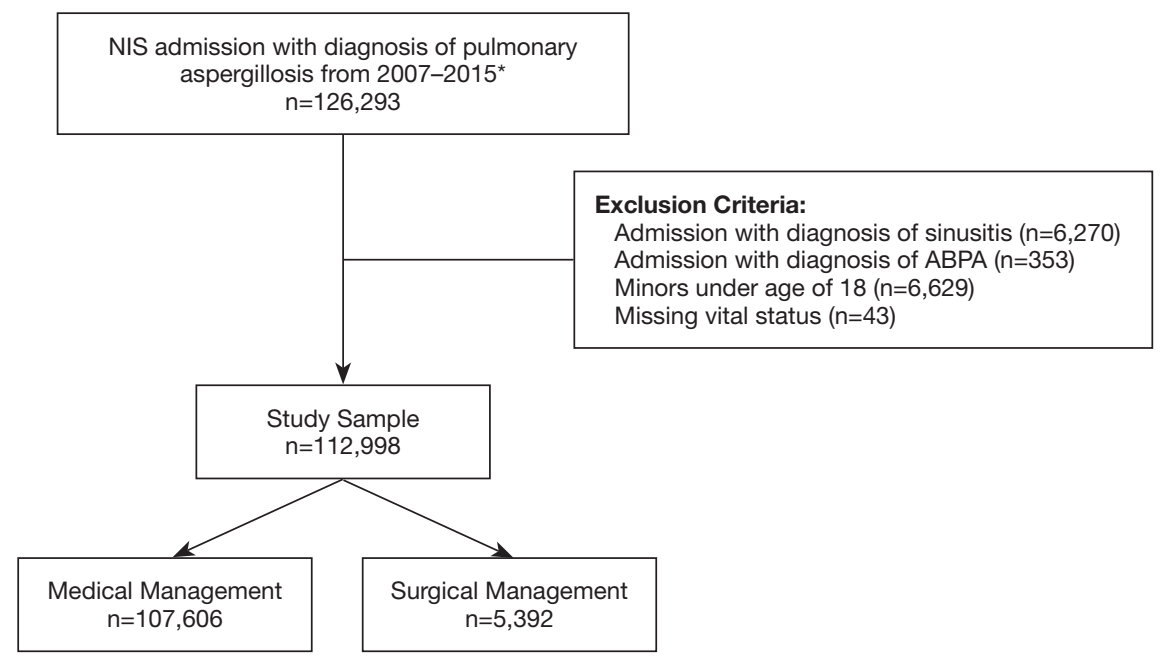

Figure 1 CONSORT diagram illustrating patient selection and cohorts. *, National Inpatient Sample (NIS) data collected through the $3^{\text {rd }}$ quarter of 2015. ABPA, allergic bronchopulmonary aspergillosis.

inpatient vital status. Additionally, using existing literature and expert opinion, pertinent patient risk factors and comorbidities were identified (Table S1) and used for our multivariable analyses.

\section{Statistical analysis}

Each year of NIS data was trend weighted so that the results would be representative of the population of US inpatients for the corresponding year. As per HCUP (Healthcare Cost and Utilization Project) guidelines, updated trend weights were applied to the NIS data dated prior to the year 2012 in order to produce frequency estimates comparable to the state-by-hospital sampling methodology used in the years following 2012 (21). Pearson's chisquare or Fisher's exact tests were utilized for categorical variables. Independent sample t-tests were used to compare continuous variables. Multivariable analysis was used to identify characteristics associated with surgical intervention and inpatient mortality. The clinical factors selected for the multivariable analysis were those that were statistically significant in univariate analysis, and the variables that were considered to be clinically important based on our experience and previous literature. As a secondary analysis, patients characterized under non-elective admissions requiring surgical intervention were used to identify patient characteristics associated with a non-elective surgical admission. Basic demographics and all variables that were statistically significant in univariate analysis were used in the multivariable logistic regression models.

All analyses were performed in IBM SPSS Statistics, Version 25 (IBM), SAS, version 9.4 (SAS Institute INC). All tests of significance were two-sided and the value of alpha for statistical significance was $\mathrm{P}<0.05$.

\section{Results}

Using population estimates, 112,928 patient admissions with the diagnosis of pulmonary aspergillosis were identified using the NIS database (Figure 1). Among these patients, 5,392 (4.8\%) underwent surgical management and the remaining 107,606 (95.2\%) underwent medical management (Table 1). Among patients managed with surgery, 2,442 (45.3\%) underwent a wedge resection, $591(11.0 \%)$ underwent a segmentectomy, 2,044 (37.9\%) underwent a lobectomy, and $315(5.8 \%)$ underwent a pneumonectomy; 2,141 (39.7\%) underwent a VATS approach and 3,251 (60.3\%) underwent an open approach. The rate of surgical intervention decreased from $5.2 \%$ in 2007 to $3.4 \%$ in $2015(\mathrm{P}<0.001)$, while the utilization of a VATS approach increased greatly from $8.1 \%$ in 2007 to $58.8 \%$ in $2015(\mathrm{P}<0.001)$ (Figure 2$)$.

Patients treated surgically were younger $(58 \mathrm{vs.} 63$ years, $\mathrm{P}<0.001)$ and more likely to be male $(61.3 \%$ vs. $54.7 \%$, $\mathrm{P}<0.001)$ compared to those treated medically (Table 1 ). They were less likely to have a non-elective admission (43.5\% vs. $84.3 \%, \mathrm{P}<0.001)$. They had a longer median length of stay (12 vs. 9 days, $\mathrm{P}<0.001)$, but were more likely 
Table 1 Baseline patient characteristics and inpatient outcomes for all patients with pulmonary aspergillosis

\begin{tabular}{|c|c|c|c|}
\hline Patient characteristics & \multicolumn{2}{|c|}{ Management } & $P$ value \\
\hline Age, y & $63(51,72)$ & $58(49,67)$ & $<0.001^{*}$ \\
\hline \multicolumn{4}{|l|}{ Gender } \\
\hline Male & $58,849(54.7)$ & 3,307 (61.3) & $<0.001^{*}$ \\
\hline Race & & & 0.242 \\
\hline White & $67,994(70.7)$ & $3,384(70.3)$ & \\
\hline Black & $13,330(13.9)$ & $680(14.1)$ & \\
\hline Hispanic & $8,077(8.4)$ & $392(8.1)$ & \\
\hline Primary expected payer & & & $<0.001^{\star}$ \\
\hline Private insurance & $30,457(28.4)$ & $2,181(40.5)$ & \\
\hline Medicaid & $13,904(12.9)$ & $665(12.3)$ & \\
\hline Medicare & $57,227(53.3)$ & $2041(37.9)$ & \\
\hline Other & $5,788(5.4)$ & $500(9.3)$ & \\
\hline Charlson comorbidity score & & & $<0.001^{*}$ \\
\hline 0 or none of the conditions & $31,409(29.2)$ & $1,585(29.4)$ & \\
\hline 1 & $35,258(32.8)$ & $2,350(43.6)$ & \\
\hline Hemoptysis & $3,101(2.9)$ & $332(6.2)$ & $<0.001^{*}$ \\
\hline \multicolumn{4}{|l|}{ Other major comorbidities } \\
\hline Lung cancer & $5,227(4.9)$ & $486(9.0)$ & $<0.001^{*}$ \\
\hline Solid organ transplantation & $9,657(9.0)$ & $290(5.4)$ & $<0.001^{*}$ \\
\hline Hematologic disease & $227,57(21.1)$ & $394(7.3)$ & $<0.001^{*}$ \\
\hline Immunodeficiency syndromes & $1,106(1.0)$ & $26(0.5)$ & $<0.001^{*}$ \\
\hline Diabetes & $17,636(16.4)$ & $616(11.4)$ & $<0.001^{*}$ \\
\hline Hemochromatosis and iron overload & $256(0.2)$ & $0(0.0)$ & $<0.001^{*}$ \\
\hline Chronic pulmonary diseases" & $50,937(47.3)$ & $3,003(55.7)$ & $<0.001^{*}$ \\
\hline Liver disease & $6,953(6.5)$ & $188(3.5)$ & $<0.001^{*}$ \\
\hline Pulmonary NTM infection & $2,427(2.3)$ & $133(2.5)$ & 0.309 \\
\hline
\end{tabular}

Table 1 (continued) 
Table 1 (continued)

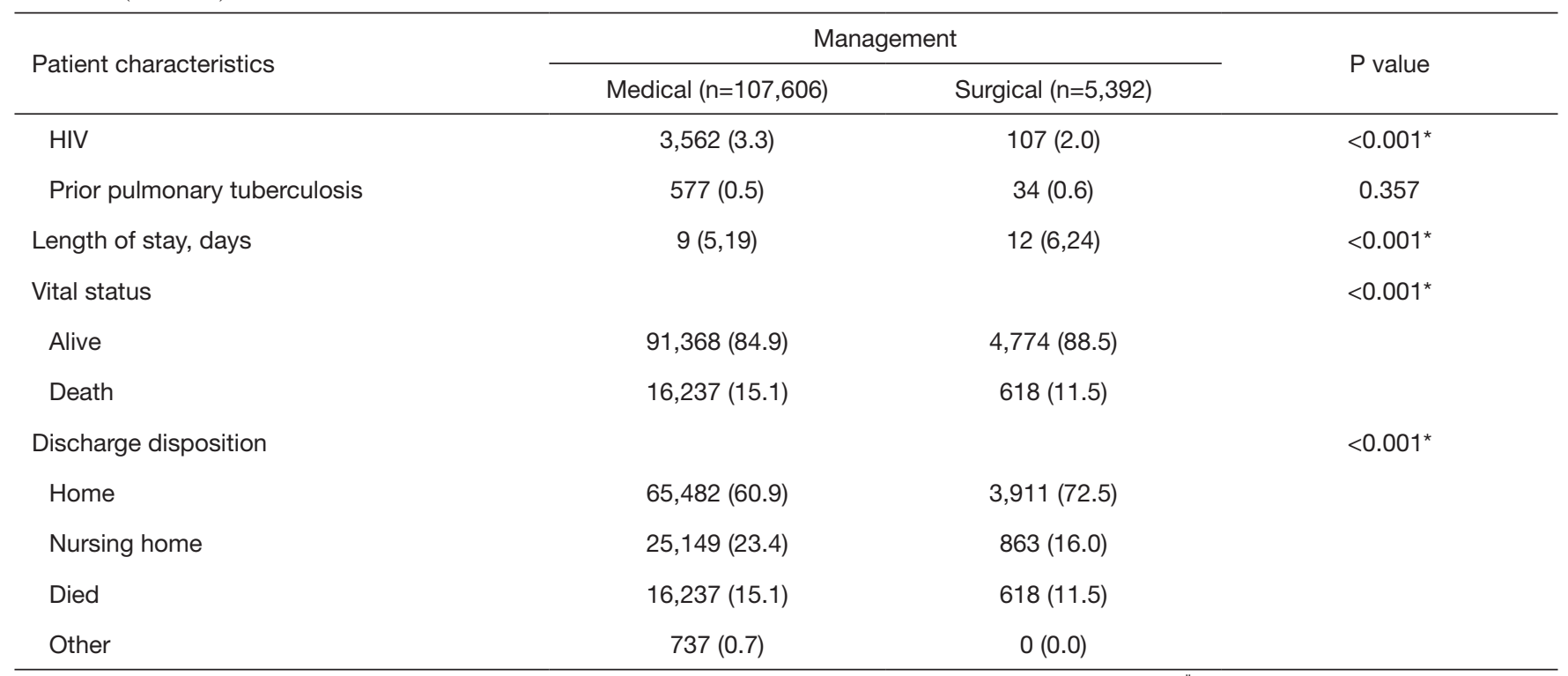

Continuous data presented as median (interquartile range). *, P value is significant at alpha 0.05 level. ", patients with $\alpha 1$ AT deficiency, pulmonary sarcoidosis, COPD, asthma, bronchiectasis, occupational and other exposure based lung diseases, interstitial lung disease, and chronic respiratory failure. VATS, video assisted thoracoscopic surgery; NTM, nontuberculosis mycobacterial; HIV, human immunodeficiency virus;

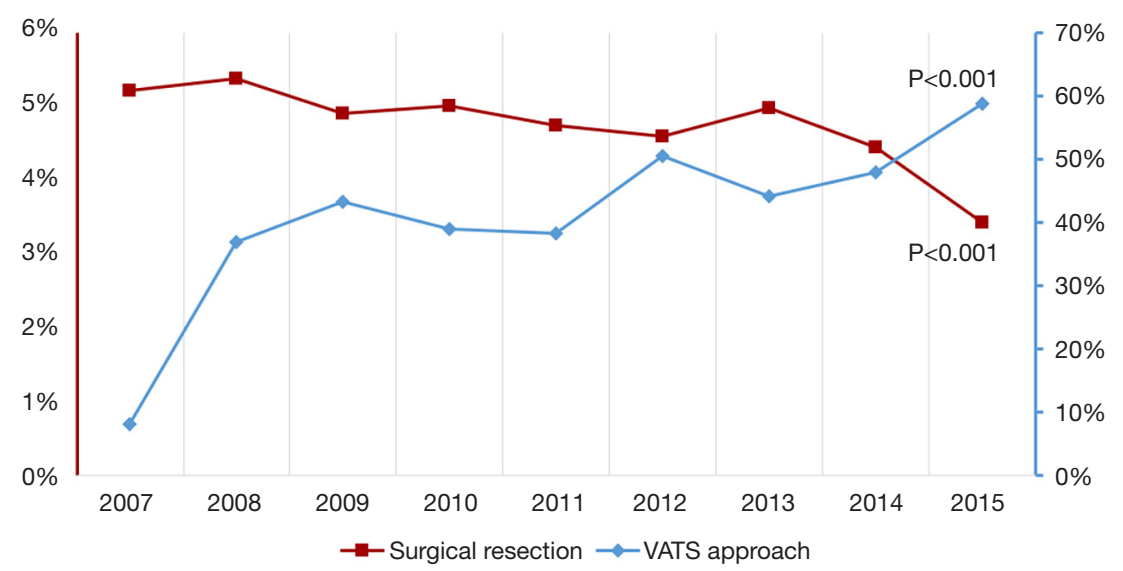

Figure 2 Trends in use of surgical resection and video-assisted thoracoscopic surgery (VATS) approach for the treatment of pulmonary aspergillosis. The use of surgery has declined over the course of the study $(\mathrm{P}<0.001)$, while at the same time, there has been a significant increase in the utilization of a VATS approach $(\mathrm{P}<0.001)$. Note, National Inpatient Sample data collected through the $3^{\text {rd }}$ quarter of 2015.

to be discharged home $(72.5 \%$ vs. $60.9 \%, \mathrm{P}<0.001)$. There was no difference in the utilization of bronchial artery embolization (BAE) between the surgically and medically treated cohorts $(2.5 \%$ vs. $2.7 \%, \mathrm{P}=0.419)$.

Multivariable analysis was used to identify predictors of surgical treatment (Table 2). Patients with hemoptysis
[AOR (adjusted odds ratio) 2.4, $\mathrm{P}<0.001$ ], lung cancer (AOR 1.59, $\mathrm{P}<0.001$ ), or chronic pulmonary diseases (AOR 1.26, $\mathrm{P}<0.001$ ) were more likely to undergo surgery. Patients with diabetes, solid organ transplantation (SOT), hematologic disease, liver disease, and a history of human immunodeficiency virus (HIV) were less likely to undergo 
Table 2 Multivariable logistic regression identifying predictors for surgical intervention in patients with pulmonary aspergillosis

\begin{tabular}{|c|c|c|}
\hline Predictors & \multicolumn{2}{|c|}{ Surgical intervention } \\
\hline Age (per 10 years) & $0.94(0.92-0.96)$ & $<0.001^{*}$ \\
\hline \multicolumn{3}{|l|}{ Gender } \\
\hline Male & 1 & \\
\hline \multicolumn{3}{|l|}{ Race } \\
\hline White & 1 & \\
\hline Black & $1.13(1.04-1.24)$ & $0.007^{*}$ \\
\hline Hispanic & $1.17(1.04-1.31)$ & $0.008^{*}$ \\
\hline \multicolumn{3}{|l|}{ Primary expected payer } \\
\hline Private Insurance & 1 & \\
\hline Medicaid & $0.78(0.71-0.87)$ & $<0.001^{*}$ \\
\hline Medicare & $0.55(0.51-0.59)$ & $<0.001^{*}$ \\
\hline Other & $1.24(1.10-1.39)$ & $<0.001^{*}$ \\
\hline \multicolumn{3}{|l|}{ Admission } \\
\hline Elective & 1 & \\
\hline Non-Elective & $0.13(0.12-0.14)$ & $<0.001^{*}$ \\
\hline Diabetes & $0.71(0.64-0.77)$ & $<0.001^{*}$ \\
\hline Chronic pulmonary diseases" & $1.26(1.19-1.35)$ & $<0.001^{*}$ \\
\hline Liver disease & $0.57(0.49-0.67)$ & $<0.001^{*}$ \\
\hline HIV & $0.63(0.51-0.77)$ & $<0.001^{*}$ \\
\hline Prior pulmonary tuberculosis & $1.11(0.77-1.59)$ & 0.601 \\
\hline
\end{tabular}

*, P value is significant at alpha 0.05 level; ", patients with $\alpha 1$ AT deficiency, pulmonary sarcoidosis, COPD, asthma, bronchiectasis, occupational and other exposure based lung diseases, interstitial lung disease, and chronic respiratory failure. VATS, video assisted thoracoscopic surgery; HIV, human immunodeficiency virus. 
surgery. Patients with Medicaid (AOR 0.78, $\mathrm{P}<0.001$ ) or Medicare (AOR 0.55, $\mathrm{P}<0.001$ ) were less likely to undergo surgery than those with private insurance.

\section{Inpatient mortality}

Overall, surgically managed patients had a lower inpatient mortality when compared to those treated medically $(11.5 \%$ vs. $15.1 \%, \mathrm{P}<0.001)$ in univariate analysis, but this finding did not persist in multivariable analysis (AOR 0.97, $\mathrm{P}=0.509$ ) (Table S2). Risk factors associated with increased mortality in multivariable analysis included older age (per 10 years change, AOR 1.19, $\mathrm{P}<0.001$ ), non-elective admission (AOR 1.35, $\mathrm{P}<0.001$ ), lung cancer (AOR 1.57, $\mathrm{P}<0.001$ ), hematologic disease (AOR 1.67, $\mathrm{P}<0.001$ ), and liver disease (AOR 3.47, $\mathrm{P}<0.001$ ).

Within the surgery cohort, there was a trend towards lower inpatient mortality in patients undergoing a VATS approach compared to an open approach $(10.5 \%$ vs. $12.2 \%$, $\mathrm{P}=0.070$ ). After adjusting for confounding variables in multivariable analysis, there was indeed a mortality benefit to a VATS approach compared to an open approach (AOR 0.77, $\mathrm{P}=0.001$ ) (Table 3). Patients undergoing a pneumonectomy had far greater mortality than those undergoing a wedge resection $(25.3 \%$ vs. $12.3 \%, \mathrm{P}<0.001)$. In multivariable analysis, a pneumonectomy was associated with a higher inpatient mortality compared to wedge resection (AOR 2.19, $\mathrm{P}<0.001$ ), but segmentectomy and lobectomy were not. Patients with history of SOT, lung cancer, hematologic disease, tuberculosis, or HIV had a higher mortality. Non-elective admission was associated with significantly higher mortality $(38.8 \%$ vs. $21.3 \%$, $\mathrm{P}<0.001)$ compared to elective admissions, a finding that persisted in multivariable analysis (AOR 7.26, $\mathrm{P}<0.001$ ).

\section{Non-elective admission}

Among patients undergoing surgery, 2,346 (43.5\%) were categorized under a non-elective admission. In a secondary analysis, patients who were not white or did not have private insurance were more likely to have a non-elective admission (Table S3). Patients who underwent pneumonectomy were more likely to have a non-elective admission (AOR 1.61, $\mathrm{P}<0.001)$. Hemoptysis was associated with non-elective surgical admission (AOR 2.24, $\mathrm{P}<0.001$ ), as was history of SOT (AOR 2.88, $\mathrm{P}<0.001$ ), liver disease (AOR 2.75, $\mathrm{P}<0.001$ ), HIV (AOR 4.62, $\mathrm{P}<0.001$ ), and hematologic disease (AOR 2.33, $\mathrm{P}<0.001)$.

\section{Discussion}

In this study, we analyzed national treatment patterns for the management of pulmonary aspergillosis and found high inpatient mortality rates in both medically and surgically treated patients. The use of surgery has declined over the last several years, while at the same time, there has been a significant increase in the utilization of a VATS approach.

We did not find a difference in inpatient mortality between the surgically (11.5\%) and medically (15.1\%) treated cohorts in multivariable analysis, despite medical treatment for IPA being traditionally associated with higher overall mortality rates compared to surgical treatment (6,11-14). Previous studies have shown much higher mortality rates for patients treated medically, up to $36.7 \%$ inpatient mortality in patients treated with intravenous antifungal therapy (15), and similar mortality rates for surgically treated patients, including a $10 \%$ perioperative mortality rate in recent case series $(13,14)$. Our study was able to control for key confounding variables, namely

Table 3 Multivariable logistic regression identifying predictors of mortality for patients with pulmonary aspergillosis who underwent surgical resection

\begin{tabular}{|c|c|c|c|c|c|}
\hline Predictors & \multicolumn{3}{|c|}{ Descriptive statistics } & \multicolumn{2}{|c|}{ Multivariable predictors of mortality } \\
\hline $\mathrm{Age}^{\dagger}$ & $58(48,67)$ & $63(55,73)$ & $<0.001^{*}$ & $1.48(1.34-1.63)$ & $<0.001^{*}$ \\
\hline Gender & & & 0.134 & & \\
\hline Male & $2,910(61.0)$ & $396(64.1)$ & & 1 & \\
\hline
\end{tabular}

Table 3 (continued) 
Table 3 (continued)

\begin{tabular}{|c|c|c|c|c|c|}
\hline Predictors & \multicolumn{3}{|c|}{ Descriptive statistics } & \multicolumn{2}{|c|}{ Multivariable predictors of mortality } \\
\hline Race & & & $0.030^{*}$ & & \\
\hline White & $2,968(70.0)$ & $416(72.3)$ & & 1 & \\
\hline Black & $616(14.5)$ & $65(11.3)$ & & $0.63(0.47-0.86)$ & $0.004^{*}$ \\
\hline Asian/Pacific Islander & $178(4.2)$ & $30(5.2)$ & & $0.66(0.42-1.04)$ & 0.076 \\
\hline Others & $142(3.3)$ & $10(1.7)$ & & $0.40(0.20-0.79)$ & $0.009^{*}$ \\
\hline Primary expected payer & & & $<0.001^{*}$ & & \\
\hline Private Insurance & $1,983(41.6)$ & $198(32.0)$ & & 1 & \\
\hline Other & $465(9.8)$ & $35(5.7)$ & & $0.52(0.35-0.81)$ & $0.003^{*}$ \\
\hline Admission & & & $<0.001^{*}$ & & \\
\hline Elective & $1,846(38.7)$ & $500(80.9)$ & & 1 & \\
\hline Non-elective & $2,923(61.3)$ & $118(19.1)$ & & $7.26(5.77-9.15)$ & $<0.001^{*}$ \\
\hline Lung resection type & & & 0.070 & & \\
\hline Open & $2,858(59.9)$ & $393(63.6)$ & & 1 & \\
\hline VATS & $1,917(40.1)$ & $225(36.4)$ & & $0.77(0.62-0.96)$ & $0.001^{*}$ \\
\hline Extent of surgery & & & $<0.001^{\star}$ & & \\
\hline \multicolumn{6}{|l|}{ Other major comorbidities } \\
\hline Lung cancer & 409 (8.6) & $541(87.5)$ & $0.001^{*}$ & $1.89(1.40-2.56)$ & $<0.001^{\star}$ \\
\hline Solid organ transplantation & $224(4.7)$ & $66(10.7)$ & $<0.001^{*}$ & $1.79(1.26-2.54)$ & $0.001^{*}$ \\
\hline Liver disease & $153(3.2)$ & $35(5.7)$ & $0.002^{*}$ & $1.60(1.01-2.53)$ & $0.046^{\star}$ \\
\hline HIV & $88(1.8)$ & $19(3.1)$ & $0.039^{*}$ & $1.99(1.04-3.49)$ & $0.016^{\star}$ \\
\hline Hematologic disease & $310(6.5)$ & $84(13.6)$ & $<0.001^{*}$ & $2.31(1.73-3.19)$ & $<0.001^{*}$ \\
\hline Diabetes & $565(11.8)$ & $51(8.3)$ & $0.008^{*}$ & $0.40(0.28-0.56)$ & $<0.001^{*}$ \\
\hline Chronic pulmonary diseases" & $2,653(55.6)$ & $351(56.8)$ & 0.561 & $1.14(0.94-1.40)$ & 0.190 \\
\hline Prior pulmonary tuberculosis & $30(0.6)$ & $4(0.6)$ & 0.096 & $3.25(1.03-10.27)$ & $0.045^{*}$ \\
\hline
\end{tabular}

${ }^{\dagger}$, Age data presented as median years (interquartile range) in descriptive statistics, and per 10 years change in multivariable analysis. *, P value is significant at alpha 0.05 level; ", Patients with $\alpha 1$ AT deficiency, pulmonary sarcoidosis, COPD, asthma, bronchiectasis, occupational and other exposure based lung diseases, interstitial lung disease, and chronic respiratory failure. VATS, video assisted thoracoscopic surgery; HIV, human immunodeficiency virus. 
several comorbidities associated with IPA and medical management (1,22-24).

We were able to identify several patient factors associated with higher inpatient mortality rates after undergoing surgery for pulmonary aspergillosis, which can aid preoperative decision making and surgical risk assessment. The patient factors included older age, male sex, and immunocompromising conditions, including hematologic diseases, SOT, HIV, liver disease, and underlying pulmonary disease including prior tuberculosis. Interestingly, prior tuberculosis was found to be a beneficial prognostic factor in terms of inpatient mortality in multivariable analysis examining the entire study cohort (including medical and surgically managed patients). This contradictory finding may be a result of surgical patients more likely to have had an underlying history of cavitary tuberculosis, whereas patients treated medically were less likely to have large cavitary lesions as a sequalae of possibly more mild tuberculosis.

We found that patients with hemoptysis and those with a history of lung cancer or chronic pulmonary disease were more likely to undergo surgery. Hemoptysis has long been an indication for surgery, however, the rationale for the increased use of surgery in patients with lung cancer or chronic pulmonary diseases is unclear (25). Presumably, these patients are more likely to undergo therapeutic surgical resection for their disease, or diagnostic surgical biopsy to distinguish focal IPA from malignant disease. On the other hand, it may be that immunosuppression due to chemotherapy for lung cancer or long-term steroids for chronic pulmonary conditions may facilitate a presentation of pulmonary aspergillosis that is more amenable to surgery (26). Further, it is possible that patients with a history of lung cancer or select lung diseases may already be under the care of thoracic surgeons.

Furthermore, non-elective admission and pneumonectomy were important risk factors for inpatient mortality among those who underwent surgery in our study, which supports several previous studies that have reported the benefits of early surgery $(9,16,18)$. Habicht and colleagues demonstrated a significant 6-month survival advantage in those treated with early surgical intervention (defined as surgical resection within a few days of establishing clinical diagnosis) over those treated with medical management only (27). A trend towards lower mortality was noted in a surgically managed cohort of patients with pulmonary aspergillosis when compared to those treated medically at 3 months post-treatment (28).
Early surgical resection may decrease the risk of fungal reactivation or life-threatening angioinvasion from occurring months after discharge $(6,29,30)$.

In patients admitted non-electively, the extent of damage caused by the invasive nature of pulmonary aspergillosis may result in significantly more extensive pulmonary resections. We found that patients who were admitted nonelectively were more likely to undergo a pneumonectomy. Similar trends have been identified in a study comparing emergent and elective surgery for pulmonary aspergillosis, reporting increased need for lobectomies rather than partial resections in the emergent setting (28). Avoiding surgery in the non-elective setting may be advisable, as it can lead to larger, more morbid resections, and is associated with higher mortality. Certainly, there are situations in which non-elective admission and surgery is unavoidable. However, in the context of a patient with a history of SOT, liver disease, HIV, or hematologic disease, one may consider intervening with surgery sooner rather than later.

This study has several limitations. Inherent to any retrospective study using a large database, there are selection biases we are unable to account for and limited clinical detail. As the NIS is a collection of admissions data, longitudinal data is not available and prevents this study from examining the long-term benefits of surgical resection. Additionally, it is possible for a single patient to appear multiple times in the database, and to have been treated differently during separate admissions. Furthermore, the database does not include the type or duration of antifungal treatment regimens used, which would certainly affect prognosis and surgical decision making (31). Further, beyond the operation performed, indications for surgery and operative details are not reported within the NIS dataset. Data pertaining to the time of diagnosis and surgery is also lacking, and if available would have provided insight into the potential benefits of early surgical intervention. Although, we did indirectly attempt to address the impact of timing and surgery by characterizing non-elective admissions for pulmonary aspergillosis requiring surgical intervention as described above. Information pertaining to patient presenting symptomology is unavailable; for instance, we are unable to differentiate the severity of hemoptysis that is recorded in the database. The lack of detail within the dataset pertaining to a patient's baseline pulmonary function or pre-existing medical comorbidities limit us from commenting on the extent and severity of a patient's condition. For instance, a patient with HIV treated with the appropriate antiviral therapy will not possess 
the same immune deficiencies as a patient non-compliant with medications. Lastly, given the limited granularity in ICD-9 codes, we are unable to distinguish IPA from more subacute or chronic forms of pulmonary aspergillosis, this will invariably limit the accuracy of our multivariable model predicting mortality. However, we have excluded ABPA and sinusitis to focus on non-allergic pulmonary manifestations of Aspergillus infection, such as IPA $(16,32,33)$. Despite these limitations, one of the greatest strengths of the NIS dataset is the ability to aggregate a large number of surgical patients that would otherwise not be possible using single institutional data.

\section{Conclusions}

Pulmonary aspergillosis is a potentially devastating disease that is prevalent in a vulnerable patient population. Early identification of patients who may ultimately require surgery may help avoid an emergent or more extensive operation associated with considerable morbidity and mortality. We have identified predictors of surgical treatment and of inpatient mortality after surgery that will help in patient selection and risk assessment, and ultimately aid in the multidisciplinary clinical decisionmaking process required to treat this opportunistic fungal infection.

\section{Acknowledgments}

Funding: None.

\section{Footnote}

Reporting Checklist: The authors have completed the STROBE reporting checklist. Available at https://dx.doi. org/10.21037/jtd-21-151

Peer Review File: Available at https://dx.doi.org/10.21037/ jtd-21-151

Conflicts of Interest: All authors have completed the ICMJE uniform disclosure form (available at https://dx.doi. org/10.21037/jtd-21-151). Mark F. Berry serves as an unpaid editorial board member of fournal of Thoracic Disease from Sep 2020 to Aug 2022. Natalie S. Lui serves as an unpaid editorial board member of Fournal of Thoracic Disease from Sep 2019 to Aug 2021. The other authors have no conflicts of interest to declare.
Ethical Statement: The authors are accountable for all aspects of the work in ensuring that questions related to the accuracy or integrity of any part of the work are appropriately investigated and resolved. The study was conducted in accordance with the Declaration of Helsinki (as revised in 2013).

Open Access Statement: This is an Open Access article distributed in accordance with the Creative Commons Attribution-NonCommercial-NoDerivs 4.0 International License (CC BY-NC-ND 4.0), which permits the noncommercial replication and distribution of the article with the strict proviso that no changes or edits are made and the original work is properly cited (including links to both the formal publication through the relevant DOI and the license). See: https://creativecommons.org/licenses/by-nc-nd/4.0/.

\section{References}

1. Soubani AO, Chandrasekar PH. The clinical spectrum of pulmonary aspergillosis. Chest 2002;121:1988-99.

2. Zilberberg MD, Nathanson BH, Harrington R, et al. Epidemiology and Outcomes of Hospitalizations With Invasive Aspergillosis in the United States, 2009-2013. Clin Infect Dis 2018;67:727-35.

3. Zmeili OS, Soubani AO. Pulmonary aspergillosis: a clinical update. QJM 2007;100:317-34.

4. Franquet T, Müller NL, Giménez A, et al. Spectrum of pulmonary aspergillosis: histologic, clinical, and radiologic findings. Radiographics 2001;21:825-37.

5. Kosmidis C, Denning DW. The clinical spectrum of pulmonary aspergillosis. Thorax 2015;70:270-7.

6. Salerno CT, Ouyang DW, Pederson TS, et al. Surgical therapy for pulmonary aspergillosis in immunocompromised patients. Ann Thorac Surg 1998;65:1415-9.

7. Tashiro M, Takazono T, Saijo T, et al. Selection of Oral Antifungals for Initial Maintenance Therapy in Chronic Pulmonary Aspergillosis: A Longitudinal Analysis. Clin Infect Dis 2020;70:835-42.

8. von Eiff M, Roos N, Schulten R, et al. Pulmonary aspergillosis: early diagnosis improves survival. Respiration 1995;62:341-7.

9. Harmouchi H, Lakranbi M, Issoufou I, et al. Pulmonary aspergilloma: surgical outcome of 79 patients in a Moroccan center. Asian Cardiovasc Thorac Ann 2019;27:476-80.

10. He B, Wan C, Zhou W, et al. Clinical profile and surgical 
outcome for different types of chronic pulmonary aspergillosis. Am J Transl Res 2019;11:3671-9.

11. Denning DW, Stevens DA. Antifungal and surgical treatment of invasive aspergillosis: review of 2,121 published cases. Rev Infect Dis 1990;12:1147-201.

12. Lin SJ, Schranz J, Teutsch SM. Aspergillosis case-fatality rate: systematic review of the literature. Clin Infect Dis 2001;32:358-66.

13. Matt P, Bernet F, Habicht J, et al. Predicting outcome after lung resection for invasive pulmonary aspergillosis in patients with neutropenia. Chest 2004;126:1783-8.

14. Matt P, Bernet F, Habicht J, et al. Short- and long-term outcome after lung resection for invasive pulmonary aspergillosis. Thorac Cardiovasc Surg 2003;51:221-5.

15. Kim A, Nicolau DP, Kuti JL. Hospital costs and outcomes among intravenous antifungal therapies for patients with invasive aspergillosis in the United States. Mycoses 2011;54:e301-12.

16. Moreau P, Zahar JR, Milpied N, et al. Localized invasive pulmonary aspergillosis in patients with neutropenia. Effectiveness of surgical resection. Cancer 1993;72:3223-6.

17. Robinson LA, Reed EC, Galbraith TA, et al. Pulmonary resection for invasive Aspergillus infections in immunocompromised patients. J Thorac Cardiovasc Surg 1995;109:1182-96; discussion 1196-7.

18. Young VK, Maghur HA, Luke DA, et al. Operation for cavitating invasive pulmonary aspergillosis in immunocompromised patients. Ann Thorac Surg 1992;53:621-4.

19. Bekkers S, Bot AG, Makarawung D, et al. The National Hospital Discharge Survey and Nationwide Inpatient Sample: the databases used affect results in THA research. Clin Orthop Relat Res 2014;472:3441-9.

20. Project HCaU. Overview of the National (Nationwide) Inpatient Sample (NIS). Available online: https://www. hcup-us.ahrq.gov/nisoverview.jsp.

21. Project HCaU. Trend Weights for HCUP NIS Data 2015. Available online: https://www.hcup-us.ahrq.gov/db/nation/ nis/trendwghts.jsp.

22. Gerson SL, Talbot GH, Hurwitz S, et al. Prolonged granulocytopenia: the major risk factor for invasive

Cite this article as: Patel DC, Bhandari P, Epstein DJ, Liou DZ, Backhus LM, Berry MF, Shrager JB, Lui NS. Surgical resection for patients with pulmonary aspergillosis in the national inpatient sample. J Thorac Dis 2021;13(8):4977-4987. doi: $10.21037 /$ jtd-21-151 pulmonary aspergillosis in patients with acute leukemia. Ann Intern Med 1984;100:345-51.

23. Segal BH, Walsh TJ. Current approaches to diagnosis and treatment of invasive aspergillosis. Am J Respir Crit Care Med 2006;173:707-17.

24. Denning DW, Follansbee SE, Scolaro M, et al. Pulmonary aspergillosis in the acquired immunodeficiency syndrome. N Engl J Med 1991;324:654-62.

25. Csekeo A, Agócs L, Egerváry M, et al. Surgery for pulmonary aspergillosis. Eur J Cardiothorac Surg 1997;12:876-9.

26. Shahid M, Malik A, Bhargava R. Bronchogenic carcinoma and secondary aspergillosis--common yet unexplored: evaluation of the role of bronchoalveolar lavage-polymerase chain reaction and some nonvalidated serologic methods to establish early diagnosis. Cancer 2008;113:547-58.

27. Habicht JM, Matt P, Passweg JR, et al. Invasive pulmonary fungal infection in hematologic patients: is resection effective? Hematol J 2001;2:250-6.

28. Chretien ML, Legouge C, Pagès PB, et al. Emergency and elective pulmonary surgical resection in haematological patients with invasive fungal infections: a report of 50 cases in a single centre. Clin Microbiol Infect 2016;22:782-7.

29. Ben-Ami R, Lewis RE, Kontoyiannis DP. Enemy of the (immunosuppressed) state: an update on the pathogenesis of Aspergillus fumigatus infection. Br J Haematol 2010;150:406-17.

30. Wu SP, Wang LW. Pulmonary Aspergillosis with Presenting Symptom of Hemoptysis. Pulmonary Aspergillosis: Springer; 2019. p. 165-244.

31. Kanj A, Abdallah N, Soubani AO. The spectrum of pulmonary aspergillosis. Respir Med 2018;141:121-31.

32. Sato M, Date H. Fungal Infections: Current Role of Thoracic Surgeons in Cases of Pulmonary Aspergillosis. Tips and Tricks in Thoracic Surgery: Springer; 2018. p. 95-108.

33. Mohapatra B, Sivakumar P, Bhattacharya S, et al. Surgical treatment of pulmonary aspergillosis: A single center experience. Lung India 2016;33:9-13. 
Supplementary

Table S1 ICD-9 medical comorbidity codes

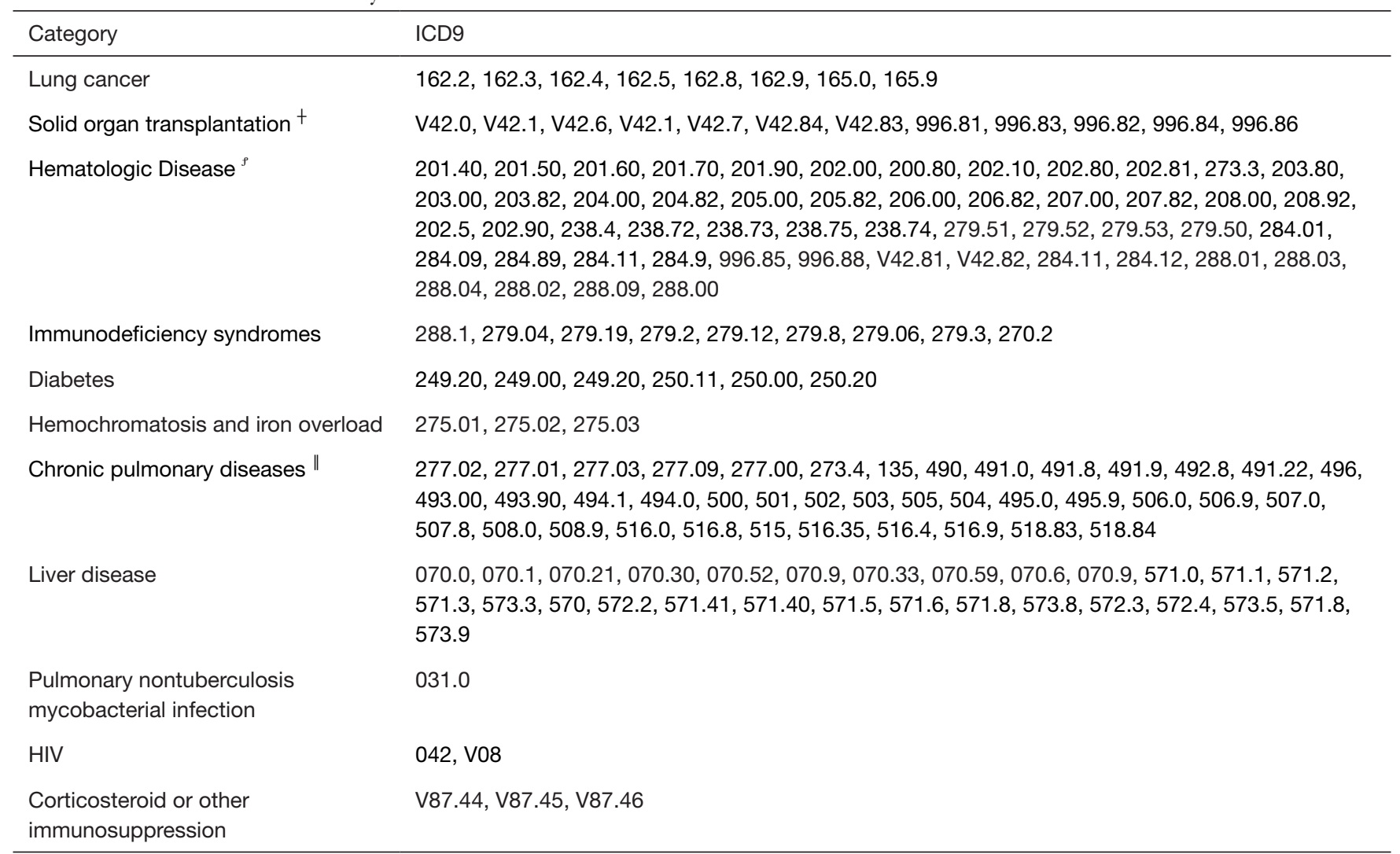

\footnotetext{
+ Status post heart, lung, kidney, intestinal or pancreas transplantation; ${ }^{\rho}$ Patients with neutropenia, bone marrow transplant, hematologic malignancies, and myeloproliferative disorders; "Patients with $\alpha 1$ AT deficiency, pulmonary sarcoidosis, COPD, asthma, bronchiectasis, occupational and other exposure based lung diseases, interstitial lung disease, and chronic respiratory failure.
} 
Table S2 Multivariable logistic regression identifying predictors of mortality for patients with pulmonary aspergillosis

\begin{tabular}{|c|c|c|c|c|c|}
\hline Predictors & \multicolumn{3}{|c|}{ Descriptive statistics } & \multicolumn{2}{|c|}{ Multivariable predictors of mortality } \\
\hline $\mathrm{Age}^{\dagger}$ & $62(51,72)$ & $65(55,74)$ & $<0.001^{\star}$ & $1.19(1.18-1.21)$ & $<0.001^{*}$ \\
\hline Gender & & & $<0.001^{*}$ & & \\
\hline Male & $52,477(54.6)$ & $9,679(57.4)$ & & 1 & \\
\hline Race & & & $<0.001^{\star}$ & & \\
\hline White & $60,677(70.6)$ & $10,700(71.3)$ & & 1 & \\
\hline Black & $12,387(14.4)$ & $1,624(10.8)$ & & $0.86(0.81-0.92)$ & $<0.001^{*}$ \\
\hline Hispanic & $7,118(8.3)$ & $1,351(9.0)$ & & $1.15(1.09-1.23)$ & $<0.001^{*}$ \\
\hline Primary expected payer & & & $<0.001^{*}$ & & \\
\hline Private Insurance & $27,860(29.0)$ & $4,778(28.4)$ & & 1 & \\
\hline Medicaid & $12,632(13.2)$ & $1,937(11.5)$ & & $0.94(0.88-0.99)$ & $0.047^{*}$ \\
\hline Medicare & $50,035(52.2)$ & $9,233(54.9)$ & & $0.90(0.86-0.95)$ & $<0.001^{\star}$ \\
\hline Other & $5,407(5.6)$ & $881(5.2)$ & & $1.04(0.95-1.13)$ & 0.406 \\
\hline Admission & & & $<0.001^{*}$ & & \\
\hline Elective & $78,268(81.6)$ & $14,510(86.2)$ & & 1 & \\
\hline Non-elective & $17,617(18.4)$ & $2,320(13.8)$ & & $1.35(1.28-1.42)$ & $<0.001^{\star}$ \\
\hline \multicolumn{6}{|l|}{ Comorbidities } \\
\hline Lung cancer & $4,568(4.8)$ & $1,146(6.8)$ & $<0.001^{\star}$ & $1.57(1.46-1.68)$ & $<0.001^{*}$ \\
\hline Solid organ transplantation & $8,692(9.0)$ & $1,255(7.4)$ & $<0.001^{\star}$ & $0.94(0.87-1.03)$ & 0.504 \\
\hline Hematologic disease & $18,653(19.4)$ & 4,497 (26.7) & $<0.001^{\star}$ & $1.67(1.60-1.74)$ & $<0.001^{*}$ \\
\hline Diabetes & $16,126(16.8)$ & $2,126(12.6)$ & $<0.001^{*}$ & $0.72(0.68-0.75)$ & $<0.001^{*}$ \\
\hline Chronic pulmonary diseases & $46,106(48.0)$ & $7,834(46.5)$ & $<0.001^{*}$ & $1.05(1.01-1.09)$ & $0.018^{*}$ \\
\hline Liver disease & $4,703(4.9)$ & $2,437(14.5)$ & $<0.001^{*}$ & $3.47(3.28-3.67)$ & $<0.001^{*}$ \\
\hline Pulmonary NTM infection & $2,264(2.4)$ & $296(1.8)$ & $<0.001^{*}$ & $0.76(0.65-0.85)$ & $<0.001^{*}$ \\
\hline Prior pulmonary tuberculosis & $559(0.6)$ & $51(0.3)$ & $<0.001^{*}$ & $0.55(0.41-0.75)$ & $<0.001^{*}$ \\
\hline
\end{tabular}

† Age data presented as median years (interquartile range) in descriptive statistics, and per 10 years change in multivariable analysis. * P-value is significant at alpha 0.05 level. NTM, nontuberculosis mycobacterial. 
Table S3 Multivariable logistic regression identifying predictors of non-elective admission for patients with pulmonary aspergillosis who underwent surgical resection

\begin{tabular}{|c|c|c|}
\hline Predictors & \multicolumn{2}{|c|}{ Non-elective surgical admission } \\
\hline Age (per 10 years) & $1.02(0.96-1.08)$ & 0.511 \\
\hline \multicolumn{3}{|l|}{ Gender } \\
\hline Male & 1 & \\
\hline \multicolumn{3}{|l|}{ Race } \\
\hline White & 1 & \\
\hline Black & $3.59(2.97-4.34)$ & $<0.001^{*}$ \\
\hline Hispanic & $1.33(1.06-1.67)$ & $0.001^{*}$ \\
\hline \multicolumn{3}{|l|}{ Primary expected payer } \\
\hline Private Insurance & 1 & \\
\hline Medicaid & $2.11(1.72-2.59)$ & $<0.001^{*}$ \\
\hline Medicare & $1.57(1.33-1.86)$ & $<0.001^{*}$ \\
\hline Other & $3.54(2.81-4.46)$ & $<0.001^{*}$ \\
\hline \multicolumn{3}{|l|}{ Extent of Surgery } \\
\hline Wedge Resection & 1 & \\
\hline Segmentectomy & $0.42(0.34-0.53)$ & $<0.001^{*}$ \\
\hline Solid organ transplantation & $2.88(2.16-3.83)$ & $<0.001^{*}$ \\
\hline Liver disease & $2.75(1.92-3.93)$ & $<0.001^{\star}$ \\
\hline HIV & $4.62(2.75-7.77)$ & $<0.001^{*}$ \\
\hline Hematologic disease & $2.33(1.84-2.96)$ & $<0.001^{*}$ \\
\hline Chronic pulmonary diseases & $0.76(0.66-0.86)$ & $<0.001^{*}$ \\
\hline
\end{tabular}

${ }^{*} \mathrm{P}$-value is significant at alpha 0.05 level. HIV, human immunodeficiency virus. 